\title{
PROCESSO ENSINO-APRENDIZAGEM E INTERAÇÃO ENTRE ALUNOS E PROFESSORES POTENCIALIZADOS PELAS TECNOLOGIAS DA INFORMAÇÃ̃ E DA COMUNICAÇÃO
}

\author{
Mara Regina Rosa Radaelli - NTE / Cruz Alta - RS - maradaelli@gmail.com \\ Fabiane Sarmento Oliveira Fruet - EAD / Mídias na Educação / UAB-UFSM - fabyfruet@ mail.ufsm.br
}

\begin{abstract}
RESUMO
Este artigo apresenta uma experiência relacionada à inserção das Tecnologias da Informação e da Comunicação (TIC) no contexto educacional. Foram abordados alguns aspectos relevantes na interação entre professor/aluno, aluno/professor e aluno/aluno, proporcionada pelas tecnologias presentes nos ambientes escolares. Além disso, destacou-se a importância do planejamento de atividades cooperativas entre os envolvidos no processo ensino-aprendizagem, por meio da metodologia Webquest. No decorrer desta investigação, foi planejado e desenvolvido o projeto Aluno Monitor, que envolveu um grupo de alunos e professores da rede estadual de ensino, da cidade de Cruz Alta - RS. Acredita-se que os resultados desta pesquisa possam contribuir para uma reflexão sobre a integração de recursos tecnológicos como suporte ao ensino-aprendizagem.
\end{abstract}

Palavras-chave: Tecnologias da Informação e da Comunicação; Processo ensino- aprendizagem; Webquest.

\section{TEACHING AND LEARNING PROCESS AND INTERACTION AMONG STUDENTS AND TEACHERS IMPROVED BY INFORMATION AND COMMUNICATION TECHNOLOGIES}

\section{ABSTRACT}

This article presents an experience related to the introduction of Information and Communication Technologies in educational context. We discuss some relevant aspects in the interaction between teacher / student, student / teacher and student / student, due to technologies found in school environments. Furthermore, we emphasized the importance of planning for cooperative activities among those involved in teaching-learning process through Webquest methodology. During this investigation, it was designed and developed the Aluno Monitor Project, which involved a group of students and teachers in state schools of Cruz Alta - RS. We believe that the results of this research may contribute to a reflection about the integration of technological resources to support for teaching and learning.

Keywords: Information and Communication Technologies; Teaching-learning process; Webquest.

\section{CONSIDERAÇÕES INICIAIS}

A Secretaria de Educação a Distância (SEED) desenvolveu o programa de distribuição de equipamentos para as escolas públicas e vem, sistematicamente, elaborando cursos de aperfeiçoamento de professores e multiplicadores. Tal Programa foi instituído pelo Decreto $\mathrm{n}^{\circ}$ 6.300, em 12 de dezembro de 2007 e se chama Programa Nacional de Tecnologia Educacional (ProInfo). O ProInfo postula a integração e articulação de três componentes: 1) A criação e instalação de salas tecnológicas (que compreende na instalação de novos equipamentos como computadores, impressoras, scaners e outros equipamentos, além de acesso à Internet); 2) A formação dos professores e outros agentes educacionais para o uso das Tecnologias da Informação e Comunicação (TIC); e 3) A disponibilização, pela SEED, de recursos educacionais multimídia e digitais, soluções e sistemas de informação às instituições de ensino, com 
o objetivo de inserir as TIC nas escolas públicas, buscando proporcionar a inclusão digital no âmbito escolar.

Diante dessa realidade, da presença de recursos tecnológicos e computadores conectados à Internet nas escolas, desenvolveu-se um projeto denominado Projeto Aluno Monitor com alunos do ensino fundamental e médio de escolas públicas estaduais na cidade de Cruz Alta - RS .

Pois, concorda-se com Perrenoud (2000, p.125), quando afirma que

\begin{abstract}
As escolas não podem mais ignorar o que se passa no mundo, que o desenvolvimento de novas tecnologias da informação e da comunicação transforma espetacularmente não só como se comunicar, mas também, a forma de trabalhar, de decidir e de pensar.
\end{abstract}

Devido a isso, é essencial desenvolver, no contexto escolar, habilidades que possibilitem aos professores e alunos interatuarem com essas tecnologias e, principalmente, aprenderem por meio destas. Por isso, concorda-se com Paiva (2002, p.07) ao enfatizar que "uma escola que não recorra, ou melhor, que não integre os novos meios informáticos, corre o risco de se tornar obsoleta."

Além disso, entende-se que a introdução das TIC na Educação está associada não apenas a mudanças tecnológicas, mas também sociais. Como muito bem expõe Perrenoud (2000, p.128), quando se refere em formar para as novas tecnologias.

Formar para as novas tecnologias é formar o julgamento, o senso crítico, o pensamento hipotético e dedutivo, as faculdades de observação e de pesquisa, a imaginação, a capacidade de memorizar e classificar, a leitura e a análise de textos e de imagens, a representação de redes, e de procedimentos e de estratégias de comunicação.

Mas, para ocorrer à introdução das TIC e que estas contribuam para a formação, Moran (2007, p.155) salienta que

\begin{abstract}
Não depende só de alta tecnologia, mas de pessoas criativas e de projetos pedagógicos institucionais bem gerenciados. (...) Bons gestores são fundamentais para dinamizar a escola, para buscar caminho, para motivar todos os envolvidos. [...] todos os envolvidos com educação são gestores. $\mathrm{O}$ professor também é gestor de pessoas, é representante institucional.
\end{abstract}

Assim, este artigo é resultado da aplicação do projeto Aluno Monitor com os alunos, em que foram relatadas situações reais do desenvolvimento desse projeto. Dessa maneira, investigou-se a implementação de atividades que envolveram os recursos tecnológicos e também a atuação dos alunos como alunos monitores, bem como, a aceitabilidade desse projeto por parte do professor.

\title{
1. Contexto da pesquisa
}

A pesquisa compreendeu fases distintas, diferenciadas pelas características de cada etapa do trabalho. O projeto Aluno Monitor foi desenvolvido pela necessidade de usar os laboratórios de informática das escolas e por ainda haver certo receio de alguns professores relacionado à mediação desse recurso tecnológico em suas práticas docentes.

Inicialmente, buscaram-se as escolas interessadas em participar do projeto e entre as que participaram, foi selecionada a Escola Estadual de Ensino Fundamental Dr. 
Gabriel Álvaro de Miranda da cidade de Cruz Alta - RS para a realização dessa pesquisa.

Em reunião com a diretora dessa escola, foi explicado o projeto, que seria um curso para os alunos, no qual eles iriam adquirir competências para assessorar os professores com relação ao uso das tecnologias presentes no laboratório de informática da escola, ao desenvolvimento de projeto de aprendizagem e de pesquisa na Internet. $\mathrm{O}$ diferencial apresentado para a diretora foi que este projeto pretendia capacitar um aluno monitor por sala de aula, visando com isso que o aluno ajudasse seus colegas, suas professoras, nas atividades no laboratório de informática da escola.

\subsection{Número de Alunos}

Foram escolhidos, pela direção e serviço de orientação da escola, 10 alunos por turno, que atendessem os seguintes requisitos: ser comunicativo, envolvido com a dinâmica das atividades da escola, demonstrar interesse de participar do curso e ser posteriormente aluno monitor assessorando as professoras nas atividades no laboratório de informática.

Todos os alunos apresentaram autorização dos pais para participar do projeto. Os alunos estavam cursando a quinta ou a sexta série do ensino fundamental, faixa etária entre 11 a 13 anos.

O curso foi realizado uma vez por semana no turno inverso que estudam na escola. As atividades do projeto se desenvolveram no primeiro semestre de 2008.

\subsection{Como se desenvolveu o curso para os Alunos Monitores}

O curso desenvolveu-se no Núcleo de Tecnologia Educacional (NTE) de Cruz Alta - RS, onde os alunos tiveram aulas de informática básica e de editor de texto (Word e Writer, Power Point e Impress - sistema operacional Windows e Linux.

Com o correio eletrônico, eles aprenderam a criar a enviar mensagens e anexos, como se deve proceder e quais os cuidados se deve ter ao pesquisar na Internet;

Além disso, desenvolveram o Projeto de Aprendizagem (PA) e aprenderam como ajudar os professores a aplicarem o PA em sala de aula. Para isso, seguiram todos os passos do projeto de aprendizagem:

- Escolha do Tema;

- Formação do Grupo;

- Levantamento das Certezas Provisórias e Dúvidas Temporárias, onde os alunos discutiram no grupo suas certezas e dúvidas em relação ao tema que iriam pesquisar;

- Em outra etapa do PA dos alunos, eles definiram as ações que iriam fazer para buscar a comprovação das suas certezas ou não e solução para suas dúvidas;

Nessa última etapa, todos os grupos realizaram pesquisas na internet sobre o tema de seus PA. Os temas escolhidos pelos grupos foram:

- A origem dos dinossauros na Terra;

- Mundo Antigo;

- Amizade;

- Importância da Física;

- Satélites;

- Chris Brown;

- Cantoras Famosas: "Fargie, Avril, Britney"; 


\title{
- Chelsea Football Club
}

Além da parte pedagógica do desenvolvimento do PA, os alunos monitores tiveram uma oficina técnica no NTE, que mostrou quais os procedimentos seguros no manuseio do computador. As aulas contaram também com dinâmicas de interação de grupo, o que propiciou o desenvolvimento de atividades que exercitaram atitudes de cooperação, coleguismo e socialização.

O PA teve sua conclusão, quando os alunos criaram uma apresentação para expor as conclusões sobre suas dúvidas e certezas após as pesquisas realizadas, onde aplicaram os conhecimentos adquiridos no decorrer do curso, usando recursos como data show, computador, som e imagens.

Outra atividade desenvolvida pelos alunos no projeto Aluno Monitor foi à criação de um blog, disponível no endereço http://rogrmo.blogspot.com, em que registraram seus projetos desenvolvidos no curso.

Os alunos monitores demonstraram muito interesse no decorrer das aulas.

\subsection{Projeto cooperativo entre professores e alunos}

A escola caminha para a cooperação profissional, segundo Perrenoud (2000, p.79). O autor ressalta também que "a divisão do trabalho pedagógico aumenta, na escola primária, com a emergência de papéis específicos e o desenvolvimento do trabalho de forma cooperativa".

Segundo, Lima (2001, p.11)

\begin{abstract}
A introdução das tecnologias da informação na Educação está associada não apenas a mudanças tecnológicas, mas também sociais. É preciso também criar ambientes especialmente destinados a aprendizagem onde os alunos possam construir os seus conhecimentos de forma cooperativa e interativa não esquecendo os estilos individuais de aprendizagem.
\end{abstract}

Neste enfoque, percebe-se a urgência da realização de projetos nas escolas, que busquem tanto a divisão de trabalhos como novos modelos de ensinar e aprender mediados pelas TIC presentes nos ambientes educacionais.

Perrenoud (2000, p.83) ressalta que

Projetos que se organizam em torno de uma atividade pedagógica precisa, como, por exemplo, a montagem de um espetáculo em conjunto, a organização de uma jornada esportiva, a criação de oficinas abertas, a criação de um jornal; a cooperação é, então, o meio para realizar um empreendimento que ninguém tem a força ou a vontade de fazer sozinho; ela se encerra no momento em que o projeto é concluído; Projetos cujo desafio é a própria cooperação e que não tem prazos precisos, já que visam a instaurar uma forma de atividade profissional interativa que se assemelha mais a um modo de vida e de trabalho do que a um desvio para alcançar um objetivo preciso.

O desenvolvimento de projetos educacionais que envolvam o uso das TIC também pode oportunizar experiências interdisciplinares. Conforme Prado (2005 apud ALMEIDA, 1999, p.02),

(...) muitas experiências têm nos revelado que o trabalho com projetos potencializa a articulação entre as áreas de conhecimento de forma integrada com as diferentes tecnologias. [...] o projeto evidencia-se uma atividade que rompe com as barreiras disciplinares, torna permeável as suas fronteiras e caminha em direção a uma postura interdisciplinar para compreender e transformar a realidade em prol da melhoria da qualidade de vida pessoal, grupal e global. 
Percebe-se que para os recursos tecnológicos serem usados na escola, é necessário o envolvimento e comprometimento dos professores com relação a metodologias e projetos que integrem estes recursos na aprendizagem dos alunos.

Nesse sentido, Lima (2001, p.12) salienta que

A eficácia da implementação e utilização do computador no espaço escolar depende, também, que os professores estejam comprometidos com as discussões sobre a importância e a necessidade de se introduzir os recursos da informática na escola neste momento da história, além é claro, conforme Klein e Ripper (1983), de "sensibilizá-los e envolvê-los com as preocupações de como utilizar o computador no ensino.

Com relação à Internet, Moran (1997 apud ROMANO, 2003, p.320) destaca que

(...) é uma ferramenta fantástica para abrir caminhos novos, para abrir a escola para o mundo, para trazer inúmeras formas de contatos com o mundo. Mas essas possibilidades só acontecem se, na prática, as pessoas estão atentas, preparadas, motivadas para querer saber, aprofundar, avançar na pesquisa, na compreensão do mundo.

Diante dos recursos tecnológicos e a Internet, presentes nos espaços educacionais, observa-se a importância dos mesmos como mediadores para ensinar e para aprender. Em que a interação entre professores e alunos pode ser potencializada a partir de metodologias inovadoras que integrem tais recursos. No entanto, para que isso ocorra, é essencial que professores e alunos tenham habilidades tecnológicas.

\subsection{Metodologia Webquest}

No ano de 1995, Bernie Dodge criou uma ferramenta, a qual batizou com o nome de Webquest. Esta ferramenta é usada para auxiliar as pesquisas na Internet de forma criativa e também ajudam a encontrar o que está consolidado e a organizar o que está confuso, caótico, disperso (MORAN, 2007).

Conforme afirma, Mercado (2004, p.159),

A metodologia Webquest busca ser efetivamente uma forma de estimular a pesquisa, o pensamento crítico, o desenvolvimento de professores, a produção de materiais e a construção de conhecimento por parte dos alunos. (...) Uma Webquest parte da definição de um tema e objetivos por parte do professor, uma pesquisa inicial e disponibilização de links selecionados acerca do assunto para consulta orientada dos alunos. Estes devem ter uma tarefa, exeqüível e interessante, que norteie a pesquisa.

$\mathrm{O}$ autor também destaca que por meio dessa metodologia "O aluno desenvolve a aprendizagem cooperativa, a pesquisa em grupo, a troca de resultados. A interação bemsucedida aumenta a aprendizagem”. (p.159) Devido a isso, tal metodologia é uma forma interessante de cooperação entre professor e aluno e entre os alunos. O professor, após criar a Webquest, pode sugerir a formação de grupos, a fim de obter soluções em conjunto para a atividade. É importante salientar que para organizar uma Webquest se deve sempre partir de um tema e propor uma tarefa que envolva a consulta de fontes de informação. 
Salateski, Pereira e Sella ressaltam a importância de conhecer a característica de cada uma das etapas da Webquest, para que se garantam os objetivos e a construção do conhecimento. As etapas são:

\begin{abstract}
Introdução: esta aba contém uma apresentação rápida do assunto ou atividade, incentivando e motivando o aluno à pesquisa. Tarefa: é a definição do que o aluno terá que realizar ou produzir para completar a atividade. Processo: este espaço traz os passos claramente organizados com links e outros recursos com as informações necessárias para levar o aluno às respostas das questões levantadas. Avaliação: apresenta os critérios e o processo de como o resultado da tarefa será avaliado e que fatores serão considerados no desenvolvimento das atividades. Conclusão: encerra a pesquisa, apresenta um resumo do propósito geral do que foi aprendido e dá indícios de novas investigações. (SALATESKI; PEREIRA; SELLA, p.06-07 - grifos em negrito nossos)
\end{abstract}

Segundo, Barros (2005) essa metodologia é uma oportunidade de realizar algo diferente para obter melhores resultados em relação à aprendizagem dos alunos e oportuniza a produção de materiais de apoio ao ensino, conforme as necessidades do professor e dos alunos. Ainda de acordo com o autor (2005, p.06),

Para os professores que estão iniciando suas produções e descobertas na Internet, a organização e o desenvolvimento de Webquests, torna-os mais seguros no emprego de recursos da web, uma vez que os professores irão implementar um material que eles mesmos construíram, sabendo assim qual será cada nó dos caminhos que os alunos percorrerão.

\title{
2. Atividade Webquest desenvolvida durante o projeto aluno monitor
}

A atividade Webquest foi desenvolvida para alunos da terceira série do Ensino Fundamental da Escola de Ensino Fundamental Dr. Gabriel Álvaro de Miranda e teve como objetivos:

- Proporcionar aos alunos da terceira série do Ensino Fundamental uma atividade no NTE de Cruz Alta, RS, com o auxílio dos alunos que participaram do Projeto Aluno Monitor.

- Possibilitar aos alunos a realização de uma atividade on-line - Webquest.

- Realizar as atividades propostas na Webquest, a fim de desenvolver habilidades de leitura, de pesquisa na internet, de atenção as orientações propostas para a realização das atividades.

- Conhecer os pontos turísticos de Cruz Alta por meio dos sites relacionados na tarefa.

- Propiciar aos alunos do Projeto Aluno Monitor exercitarem, na prática, como auxiliar no desenvolvimento das atividades pedagógicas no laboratório de informática.

Os alunos da terceira série participaram da atividade no laboratório de informática do NTE, com o auxílio dos alunos monitores, resolvendo as atividades da Webquest sobre os pontos turísticos da Cidade de Cruz Alta, RS.

A figura 1 mostra a interface de apresentação da Webquest que mediou a atividade implementada pelos alunos monitores com os alunos da terceira série do ensino fundamental. 


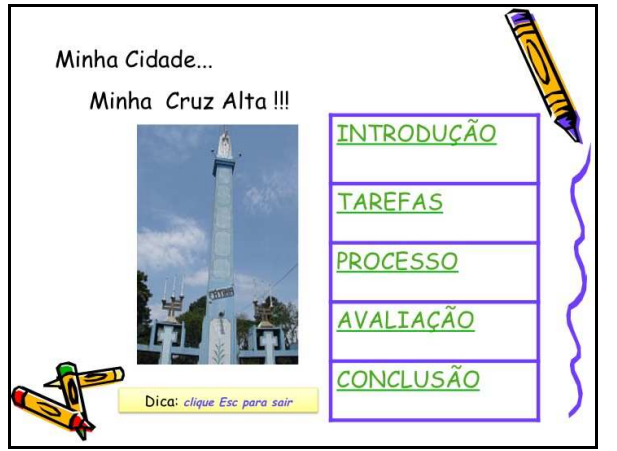

Figura 1 - Interface de apresentação da Webquest

A Webquest foi produzida pela professora-multiplicadora do NTE de Cruz Alta RS, com o auxílio da professora da terceira série da Escola de Ensino Fundamental Dr. Gabriel Álvaro de Miranda. O conteúdo para a Webquest foi sugerido pela professora da turma, pois era o conteúdo que estava desenvolvendo na semana do aniversário do Município.

Inicialmente, os alunos do Projeto Aluno Monitor realizaram as atividades propostas na Webquest, ou seja, acessaram os sites apresentado, leram e desenvolveram as atividades, a fim de conhecer as interfaces da mesma.

Em outro momento, a professora da terceira série do Ensino Fundamental levou os alunos ao laboratório de informática do NTE para realizarem as atividades propostas na Webquest, assessorada pelos alunos monitores.

Os alunos monitores auxiliaram os alunos da terceira série para ligarem os computadores, iniciarem a leitura da Webquest e visitarem os sites citados na introdução da atividade (figura 2).

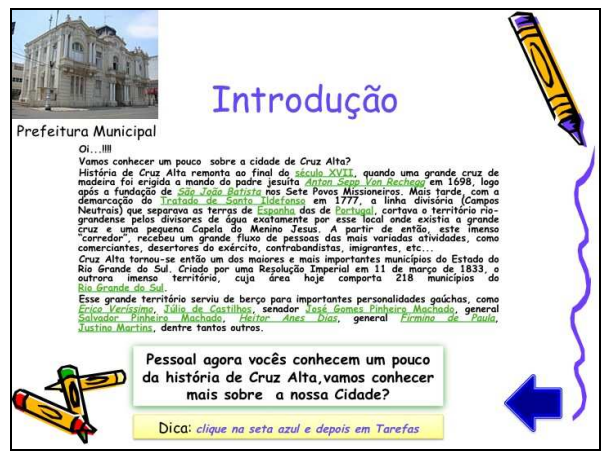

Figura 2 - Introdução Webquest

Os alunos monitores se dividiram e apresentaram as orientações da atividade Webquest (figura 3), separadamente, para cada grupo de alunos da terceira série.

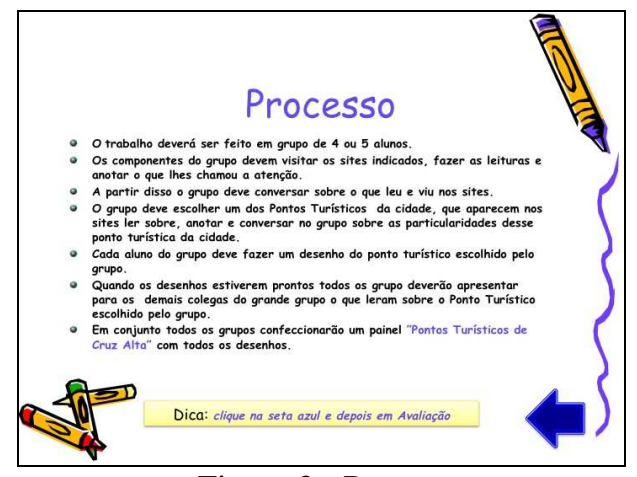

Figura 3 - Processo 
As atividades foram desenvolvidas em grupos. Cada aluno monitor assessorou um grupo de alunos da terceira série, para que acessassem os sites e encontrassem os pontos turísticos do Município de Cruz Alta, com o acompanhamento da professora da turma e da multiplicadora do NTE. O enunciado de tais atividades está na interface Tarefas da Webquest (figura 4).

A tarefa de número três (figura 4) foi realizada pelos alunos em sala de aula com o acompanhamento da professora da turma e dos alunos monitores.

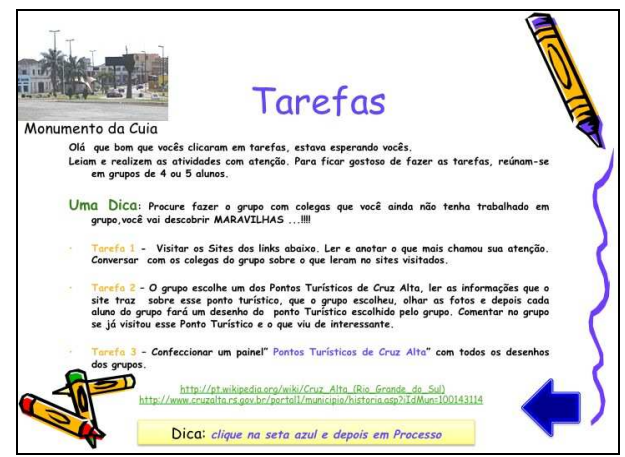

Figura 4 - Tarefas

Durante a atividade da Webquest, os alunos da terceira série demonstraram envolvimento e vontade em realizar as tarefas solicitadas. A atividade Webquest possibilitou potencializar a interatividade e a interação entre os alunos (figura 5) e entre alunos e professoras. Uma vez que a curiosidade dos alunos em poderem visitar todos os pontos turísticos da cidade virtualmente, despertou neles a necessidade de interagirem com o grupo e clicarem nos links disponíveis na Webquest.
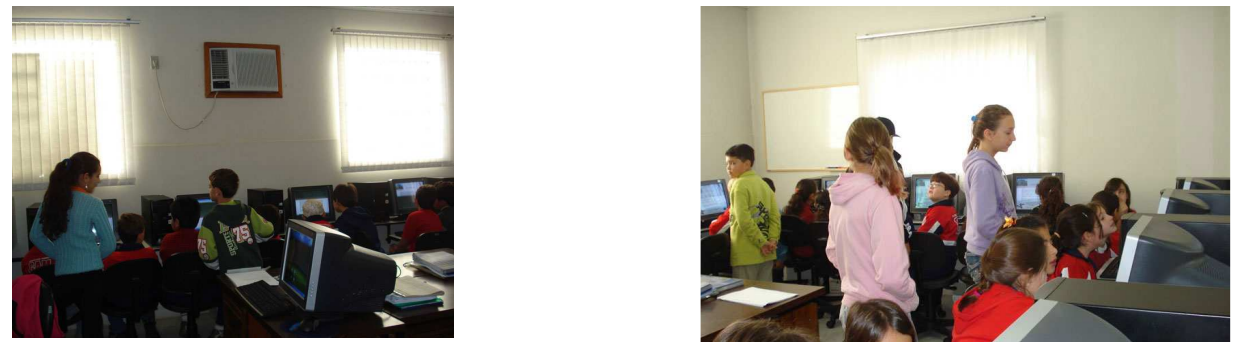

Figura 5 - Alunos monitores interagindo com os alunos da terceira série.

A avaliação dos alunos da terceira série foi realizada pelo aluno monitor que assessorava o grupo, seguindo os critérios estipulados na Webquest e orientação das professoras. Os critérios de avaliação (figura 6) foram apresentados aos alunos da terceira série no início da atividade.

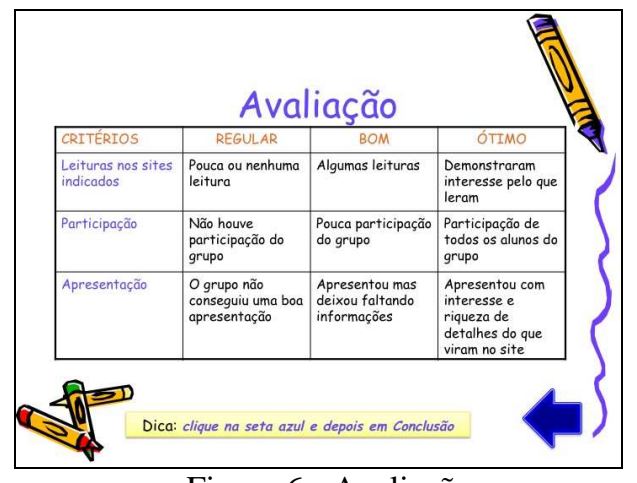

Figura 6 - Avaliação 
A figura 7 mostra a interface da Webquest com a conclusão, a qual tem como finalidade mostrar para o aluno que a realiza, o que se espera como resultado ao término das atividades propostas no decorrer das fases da Webquest.

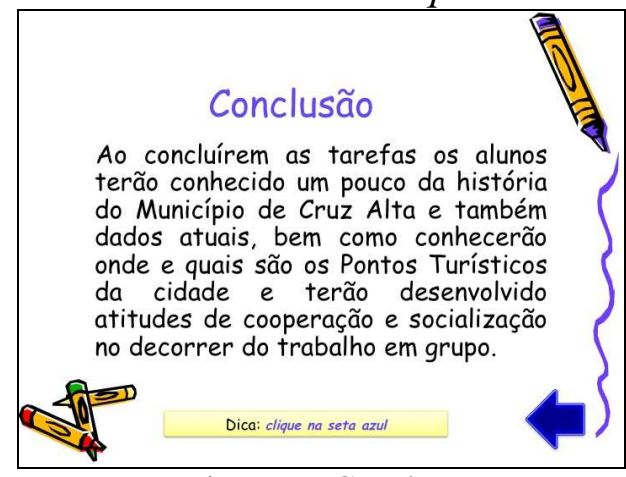

Figura 7 - Conclusão

Depois de realizadas as atividades com os alunos da terceira série, os alunos monitores deram entrevista para o jornal da cidade, momento que demonstraram segurança ao falar sobre o que aprenderam ao participarem deste projeto.

\section{As experiências dos alunos com as TIC: análise dos resultados}

Por meio das observações feitas durante o desenvolvimento do Projeto Aluno Monitor e a aula no laboratório de informática do NTE para a aplicação da Webquest, foi possível perceber algumas situações, entre as quais se destaca o empenho dos alunos monitores em ajudar os alunos da terceira série a realizarem as atividades. Notou-se também a receptividade dos alunos da terceira série ao receberem a ajuda dos alunos monitores.

Além disso, verificou-se que as aulas no laboratório de informática foram para as crianças aulas diferentes. As crianças mostraram-se muito motivadas para a realização da atividade proposta. Para alguns que não possuem computador em casa, o ato de "desvendá-lo" é também uma tarefa desafiadora.

As crianças demonstraram interesse no decorrer das atividades da Webquest. Observou-se também que as crianças que já possuem familiaridade com o computador lideravam o grupo, orientando muitas vezes os colegas através de dicas sobre como manuseá-lo. Além disso, percebeu-se que os alunos monitores, em cooperação com a professora da turma da terceira série, conseguiram conduzir, satisfatoriamente, os alunos em cada etapa da Webquest.

Por meio do uso pedagógico das TIC, este estudo mostrou a importância da integração entre professores e alunos no desenvolvimento de novos projetos com metodologias diferenciadas para ensinar e aprender. Verificou-se também que o aluno se sente valorizado em poder demonstrar seu conhecimento, ao contribuir e cooperar com o professor. Em relação ao posicionamento do professor, foi possível observar que o mesmo interagiu com o aluno monitor e demonstrou uma boa receptividade com o auxílio do mesmo na condução das tarefas.

Assim, constatou-se que a integração das TIC em atividades pedagógicas possibilita maior interação entre professor e alunos (monitores e da terceira série) e representa uma proposta de mudança nas concepções educativas. 


\section{CONSIDERAÇÕES FINAIS}

Este estudo permitiu constatar que é possível desenvolver atividades pedagógicas em que o conhecimento do aluno pode ser aplicado de maneira cooperativa, como um aliado do professor no processo ensino-aprendizagem.

Os alunos que participaram do Projeto Aluno Monitor adquiriram competências e conhecimentos de editor de texto, pesquisa na internet, interatividade com $o$ computador e atitudes de cooperação para assessorar as professoras em atividades no laboratório de informática e aplicação de projetos de aprendizagem. Uma vez que desenvolveram atitudes de cooperação e interação entre colegas e com os professores das diversas disciplinas. O diferencial do projeto é que em cada sala de aula tenha um aluno monitor. Isso possibilitará aos professores usarem os laboratórios de informática como recursos de aprendizagem para seus alunos, assessorados pelo aluno monitor.

Durante o desenvolvimento do Projeto Aluno Monitor, os alunos participantes apresentavam desenvoltura e certa facilidade na interatividade com o computador, bem como na navegação em sites da Internet, o que resultou em agilidade na realização das atividades propostas, com uma constante interação entre todos. Isso possibilitou com êxito a realização de todas as etapas do projeto de aprendizagem desenvolvido no decorrer do Projeto Aluno Monitor.

Então, acredita-se ser essencial o desenvolvimento de atividades educacionais mediadas por recursos tecnológicos, as quais apresentem um sentido para os alunos. Assim, este estudo sugere que tais atividades, onde alunos e professores interajam de forma cooperativa, por meio de metodologias criativas e adequadas, apresentam-se como recurso para potencializar o ensino-aprendizagem.

\section{REFERÊNCIAS BIBLIOGRÁFICAS}

ALMEIDA, M. E. B. Projeto: uma nova cultura de aprendizagem. 1999. Disponível em: <http://www. proinfo.gov.br>. Acesso em: 04 set. 2009.

BARROS, G. C. Webquest: metodologia que ultrapassa os limites do ciberespaço. Escola Software Livre - Inclusão digital nas escolas públicas. Paraná, nov. 2005. Disponível em: <http://www.iep.uminho.pt/tce2ecc/pdfs/webquestgiliancris.pdf>. Acesso em: 27 jul. 2009.

DECRETO No 6.300, DE 12 DE DEZEMBRO DE 2007 - Dispõe sobre o Programa nacional de Tecnologia Educacional - Proinfo. Disponível em: <http://www.planalto.gov.br/ccivil_03/_Ato2007-2010/2007/Decreto/D6300.htm>

Acesso em: 25 out. 2010.

DODGE, B. Webquest. Disponível em: 〈http://webquest.org/index.php>. Acesso em: 26 ago. 2009.

LIMA, P. R. T. Novas tecnologias da informação e comunicação na educação e a formação dos professores nos cursos de licenciatura do Estado de Santa Catarina. Dissertação para título de Mestre em Ciência da Computação. Universidade Federal de Santa Catarina, Florianópolis. 2001. Disponível em: <http://www.inf.ufsc.br/ edla/orientacoes/patricia.pdf>. Acesso em: 17 set. 2009. 
MERCADO, L. P. L. Tendências na Utilização das Tecnologias da Informação e Comunicação na Educação, Maceió. 2004. Disponível em: <http://books.google. com.br/books?id=xlLQIlUxnyMC\&pg=PA151\&dq=webquest\&hl=ptBR\&ei=OrPETPu zD4K01QfA0ZwD\&sa=X\&oi=book_result\&ct=result\&resnum=4\&ved=0CDcQ6AEwA

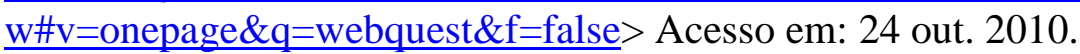

MORAN, J. M. A educação que desejamos: novos desafios e como chegar lá. São Paulo: Papirus. 2007. Disponível em: 〈http://www.eca.usp.br/prof/moran/utilizar.htm>. Acesso em: 24 out. 2009.

PAIVA, J. As Tecnologias de Informação e Comunicação: Utilização pelos Professores. Lisboa. 2002. Disponível em: 〈http://nautilus.fis.uc.pt/cec/estudo/dados/estudo.pdf> Acesso em: 12 out. 2010.

PERRENOUD, P. Dez novas competências para ensinar. Porto Alegre: Artes Médicas Sul, 2000.

PRADO, M. E. B. Articulações entre áreas de conhecimento e tecnologia: articulando saberes e transformando a prática / integração das tecnologias na educação. Secretaria de Educação a Distância. Brasília: Ministério da Educação, 2005.

ROMANO, R. S. Ambientes virtuais para aprendizagem colaborativa no ensino fundamental. In: DIAS, P. e FREITAS, C.V. de. (Org.). III Conferência Internacional de Tecnologia de Informação e Comunicação na Educação e $5^{\circ}$ Simpósio Internacional em Informática Educativa, Challenges. Braga: Centro de Competência Nónio Século XXI da Universidade do Minho, 2003. Disponível em: $<$ http://www.nonio.uminho.pt/challenges/05comunicacoes/Tema3/03RosanaRomano.pdf >. Acesso em: 20 set. 2009.

SALATESKI, C. A; PEREIRA, P. S; SELLA, A. E. Webquest valorizando Matrizes no Contexto da Educação Matemática. Disponível em: $<$ http://www.diaadiaeducacao.pr.gov.br/portals/pde/arquivos/19516.pdf?PHPSESSID=2010022609222258> Acesso em: 24 out. de 2010. 